\title{
Weed Communities in Urban Horticultural Productions in the City of Buenos Aires
}

\author{
Civeira G*, Paglieri L, Martinez P and Carloni C \\ Faculty of Agriculture and Agri food Sciences, University of Morón (UM), Argentina
}

*Corresponding author: Civeira G, Faculty of Agriculture and Agri food Sciences, University of Morón (UM), Argentina

\begin{abstract}
Changes observed in many plant communities are due to the replacement of some species by others over time and due to disturbances, such as management or crop type. The San Justo Training and Demonstration Center is a complex of plots containing a great diversity of vegetables and management methods in the same site, allowing a joint analysis on the effect of different management practices on plant communities. In this sense, the objectives of this work were: 1) To analyze the weed communities in the areas adjacent to the plots destined to different uses in Buenos Aires and 2) To evaluate the degree of maturity of the vegetal communities and different uses in urban horticulture garden. Surveys were carried out in three sectors of the site coinciding with the edges of the plots of the demonstration center. The variables measured were frequency, floristic diversity or richness, coverage of each species and total community coverage in relation to each use (semi-covered fallow, weeding, intensive horticulture and artificial trees). The plot with semi-covered fallow presented a higher frequency of appearance of Lolium multiflorum and Trifolium Repens. In horticultural use a high frequency of Oxalis latifolia and Taraxacum officinale is observed, both species are fertile soil indicators. Lolium multiflorum were found as dominant (in number of individuals) in almost all the samplings. When the disturbances are reduced or are practically zero, the appearance of perennial species is observed, demonstrating a greater advance in the succession process.
\end{abstract}

Keywords: Urban Agriculture; Ecosystem; Disturbances; Quantitative Measurements

\section{Introduction}

The changes suffered by ecosystems can be due to two types of situations: those that apparently repeat themselves through more or less regular cycles, those that do not persist and those that occur in environments without major disturbances, the last ones present a gradual sequence and directional stages conditioning the following stages. In the latter case, the ecological succession comes into play, and makes changes that can be observed in many communities due to the substitution of some species for others as time goes by Malacalza [1], Nichols et al. [2]. The processes of ecological succession can generate varied effects on the floristic composition of a specific plant community, based on the existence of a series of factors, including the frequency and intensity of disturbances. The latter tends to acquire greater importance when we study conformed or modified communities by anthropic action, or when studying lands merely destined to activities that imply soil tillage (practically constant modification of the landscape). Under this last criterion researchers included agricultural, livestock, horticultural and similar soils use [3-5]. Disturbances in ecosystems can be generated for different reasons, as well as vary in extent, frequency and intensity. There can even be disturbances of different types, or of the same type but in two or more locations within the same space. Consequently, there will be several succession processes, giving rise to floristic compositions that not only vary with respect to the original (existing vegetation prior to the disturbance) but may have characteristics that distinguish one from the other. The latter is influenced mainly by specific or small extension disturbances whose origin is mainly generated by anthropic interventions $[2,4,5]$. The above is mainly observable in plots for extensive and intensive crops such as horticultural crops, where the diversity, extension of sowing and the characteristics of the same is such that its development implies the realization of activities by man that generate diverse effects in the different subplots in which the main plot is divided; thus, in the initial plot, they come to present a series of plant communities that can differ completely from each other $[3,6]$. 
In some horticultural crops, especially organic, weed management is through controlled natural processes, which are intended to copy those that occur in natural ecosystems without anthropic intervention. Also, in this type of management organic fertilizers (compost) are used to avoid the use of chemical fertilizers, therefore other agrochemicals, such as pesticides, are not used, employing other kinds of strategies to repel pests, such as the cultivation of aromatic plants [7,8]. The San Justo Demonstration and Training Center (Framework Agreement between the FAyCA of the University of Morón - INTA - Italian Hospital) is a complex of plots (approximately 40) that are independently labored by different horitculturaal producers. This property represents an opportunity to analyze the effect of horticultural management on weed communities because a great diversity of vegetables are cultivated, and above all, because they present a high heterogeneity of planting methods and agricultural management that are carried out in the same site [7].

In general, a relationship can be established between the degree of disturbances that occur in the plot of an orchard or lot of an agricultural-livestock field and what happens at the level of plant communities in the neighboring surfaces, such as edges or internal roads. The differences in anthropic action levels within the plot will affect the surrounding areas in different degrees. If the activity inside the plot is intense, outside disturbance will be greater because the frequency with which it occurs is very high, generating a mirror effect in the areas surrounding the inside plot. Opposed to this, the lower the activity or management is, the frequency of disturbances will decrease and therefore, the surface in question will possibly have a plant community with a greater degree of maturity (for example: greater number of species) than the first case cited $[4,7,9,10]$. In a similar way to what occurs in a natural ecosystem, in a horticultural production intervened by anthropic action, the concepts of ecological succession proposed by Odum and Warret [11] are applied; that is to say, the greater the maturity of an ecosystem (or the more advanced the process of succession) increases the diversity of species, the dominance is reduced, and there tends to replace annual species with perennials, with greater capacity for competition and lower capacity for colonization. This research had the following objectives: 1) To analyze the weed communities in the areas adjacent to the plots destined to different intensive uses in an urban horticultural production of Buenos Aires and 2) To evaluate the degree of maturity of the plant communities for the different uses present in the plots of the urban garden.

\section{Materials and Methods \\ Location and Characteristics of the Study Area}

The survey was conducted in the experimental garden located in the Italian Hospital of San Justo (match of the Matanza, province of Buenos Aires). The urban horticulture production is the result of an agreement between this Hospital, the University of Morón, and INTA, through the Prohuerta program. The location coordinates were: $34^{\circ} 40^{\prime} 18.8^{\prime \prime} \mathrm{S}$; + 58 $34^{\circ} 07.1^{\prime \prime} \mathrm{W}$. The data collection was carried out on October 22, 2016. On the date of survey, the temperature was $17.5^{\circ} \mathrm{C}$ and humidity of $70 \%$, without rainfall record. The studied area belongs to the Rolling Pampa region and has a temperate climate. The average annual temperature is 18 oC and the average annual rainfall corresponds to the isohyets of $900 \mathrm{~mm}$. The studied area is located in the eastern portion of the Pampean Region [12]. The soil belongs to the great group of the Vertic Argiudolls. The clay content of the Ap horizon is $28.5 \%$, and the organic content of $4.6 \%$. The textural class is silty clay loam [13].

\section{Characteristics of the Plots and Sampling Methodology}

The horticulture production presents a high level of heterogeneity among the plots, from the type of crops that are grown, type of perimeter fences (for example, without fences, fences with plants, fence with wiring of different materials) and especially the management of the crops (sowing, pest and weed control, use of fertilizers). Surveys were carried out in four sectors of the property coinciding with the edges of the plots, each of which presented, at a glance, different characteristics. These sectors were chosen in such a way that in each one a comparison could be made between plots with different uses. Around the plots there are sectors not intended for horticultural work but belong to areas such as forests with introduced species, with some level of disturbance and with almost total dominance of a couple of species. There are also sites for the implementation of species under greenhouse and attached buildings (Figure 1)

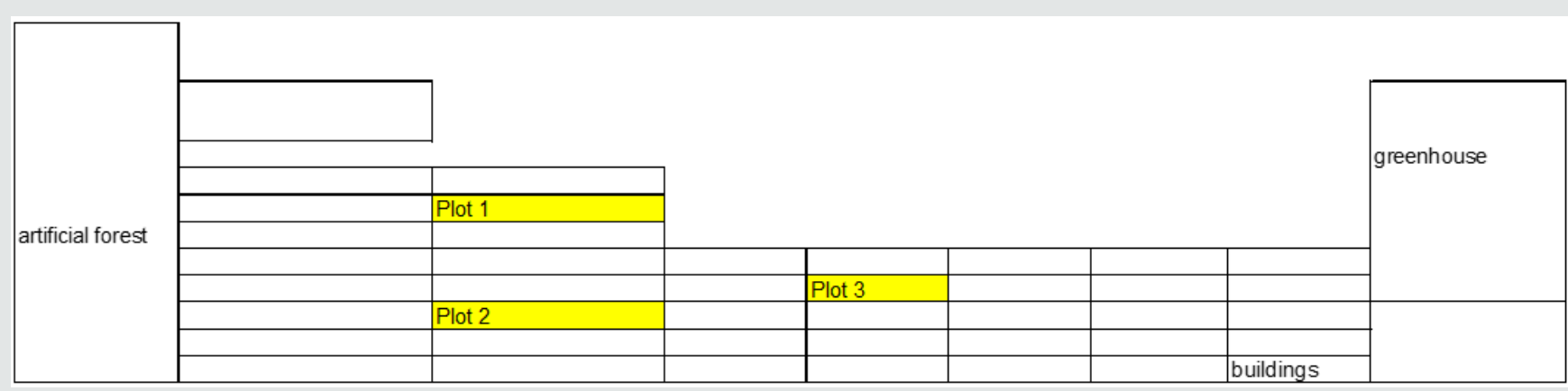

Figure 1: Plan of the plantation (horticultural production) with the evaluated plots. Plot 1: semi-covered fallow; Plot 2: weedy; Plot 3: intensive horticulture.

The studied plots presented different observables managements and uses explained in the following sentences. The Plot 1: presented a semi-covered fallow where 30 to $60 \%$ of plant material is left on the surface of the plot. Also, the plot presented a moderate proportion of soil without vegetation (combination of bare soil and covered portions of vegetation material). The plot 
presented a floristic composition of low height; the latter reflected the existence of disturbances generated by the horticultural activity that exists in the plot. However, the plot was in an area of the plantation where the activity of the producers (stakeholders) was moderate (laboured plots in coexistence with empty plots). The latter was reflected in the surface of the border limit of the plot. The plot 2 was called weedy, because it presented a floristic composition with a greater number of species than the rest of the plots. This was due to its greater degree of abandonment with respect to the rest of the plots. From the above, it is observed that there have been no disturbances during a considerable period of time in this plot. However, unlike the rest of the plots, the abandonment of the plot does not coincide with the characteristics of the vegetation in the surrounding areas. In this sense, the location of the plot was in the area of greater mobilization and activity of producers (huerteros). In addition, the vegetation presented very low height, probably due to a moderately high level of disturbances in this plot. Plot 3: was named as "intensive horticultural" due to the observables characteristics that are detailed below. In this plot, cultivated species were observed but in a lower proportion in relation to the other plots. The characteristics of the vegetation in the areas adjacent to this plot are similar to what was explained in plot 2 . The latter was probably due to the fact that plot 3 is located in a very internal place in the study plot (also plot 3) (This plot was within the area of greatest activity of the huerteros).

In each of the plots the following properties were evaluated: the frequency of appearance of a weed species in relation to the total of samples; the diversity or floristic richness that depends on the total number of species present in a community; the coverage of each of the species and the total coverage of the community in relation to each use. For the corresponding measurements, the surveys were carried out on the edges of the three selected plots of the property and the following methods were used $[14,15]$ :

A. Frames of $25 \mathrm{~cm} \times 25 \mathrm{~cm}$ were used to evaluate the frequency and diversity; the frames were randomly thrown at three sites on each of the edges of the selected plots ( 3 samplings). The counting of the plant species that were in the site was carried out in each of the sampling sites.
B. There are several methods for the evaluation of coverage, the one used in this work was the linear intercept method. This method consists in the use of a tape measure $(50 \mathrm{~cm})$ that was laid out at the edges of the plot where the survey was made. At each site, the number of species and the size of each one was measured in the length of the tape used.

\section{Results and Discussion}

In the horticultural production evaluated, the species listed in Table 1 were observed. The annual species Lolium multiflorum was dominant in all the management, followed by Trifolium repens, both species are indicators of sites with medium to high nutrient supply $[5,16]$. The frequency is the number of samples in which a species appears in relation to the total of samples obtained $[14,15]$. The results on the frequency of appearance of the species are observed in the following (Figures $2 \& 3$ ). The results obtained in the surroundings of plot 1 , showed a higher frequency of appearance of Lolium multiflorum and Trifolium Repens. Likewise, in the semi-covered fallow and in the weedy plot, a high frequency of the Lactuca virosa species was also observed. In horticultural use, there is a high frequency of appearance of Oxalis latifolia and Taraxacum officinale, both fertile soil indicator species, which can be associated with a greater use of amendments and a higher primary productivity under this in this management [17].

Table 1: Floristic composition of the horticultural production evaluated.

\begin{tabular}{|c|}
\hline Facelis retusa \\
\hline Lactuca Virosa \\
\hline Lolium multiflorum \\
\hline Oxalis latifolia \\
\hline Stelaria media \\
\hline Sonchus oleraceus \\
\hline Taraxacum officinale \\
\hline Trifolium repens \\
\hline Verónica arvensis \\
\hline
\end{tabular}

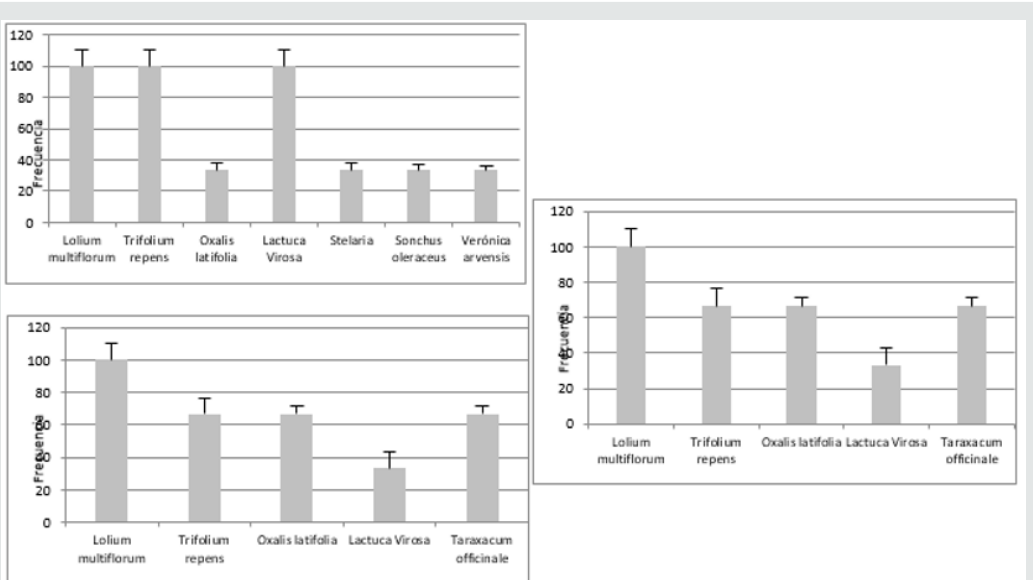

Figure 2: Frequency of the appearance of the species according to the use type: a) semi-covered fallow (Plot 1); b) weedy (Plot 2); c) intensive horticulture (Plot 3). 

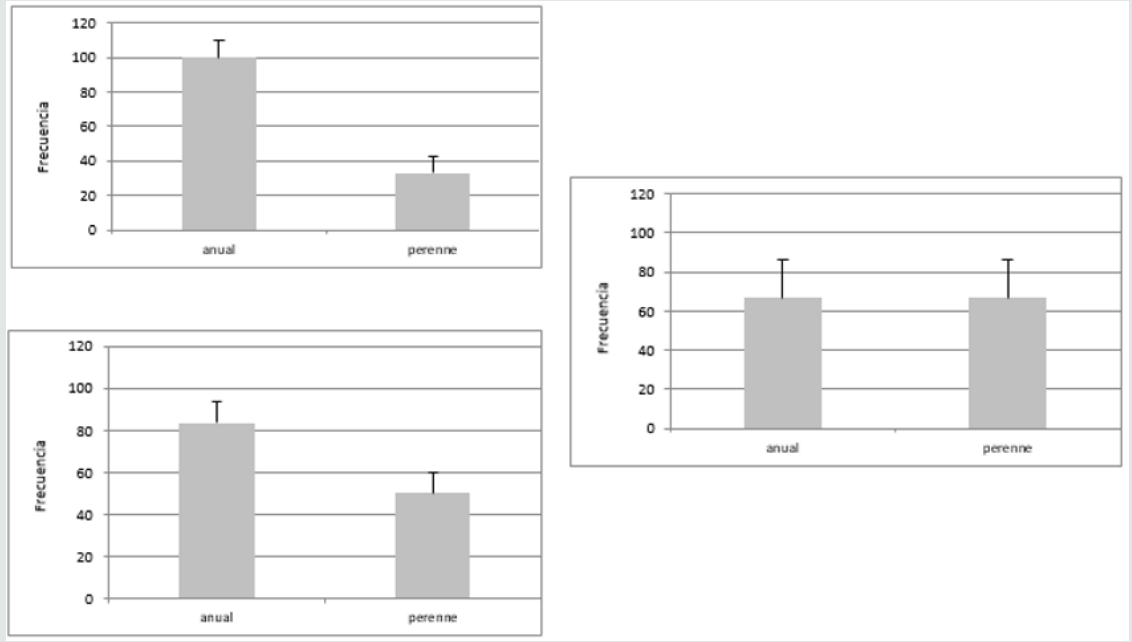

Figure 3: Frequency of the appearance of plant species according to the type of species (annual or perennial): a) semi-covered fallow (Plot 1); b) weedy (Plot 2); c) intensive horticulture (Plot 3).
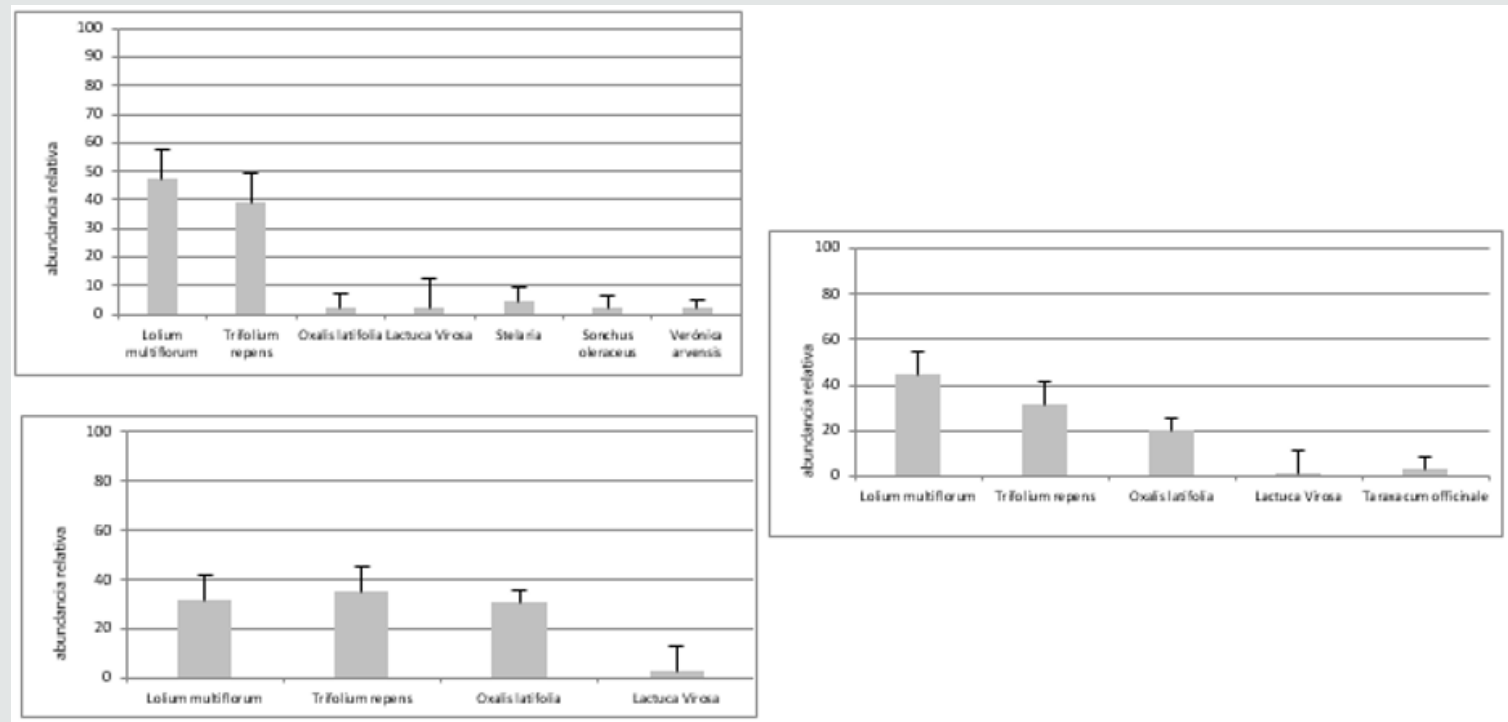

Figure 4: Distribution of relative abundances of the species according to the type of use: a) semi-covered fallow (Plot 1); b) weedy (Plot 2); c) intensive horticulture (Plot 3).

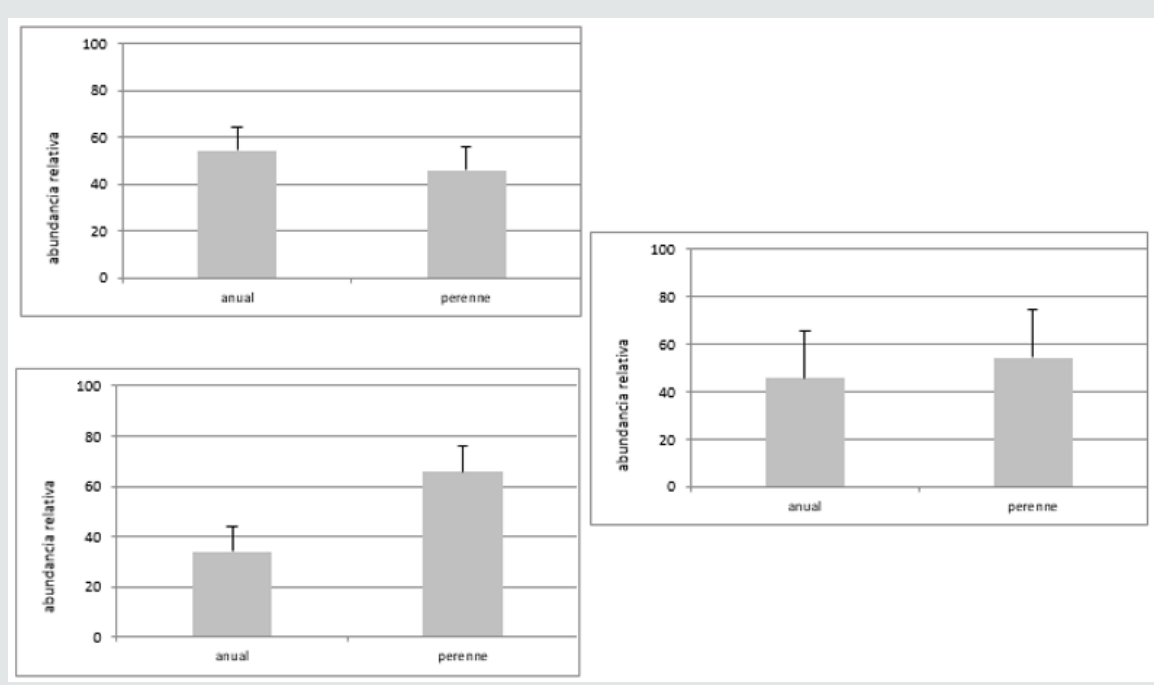

Figure 5: Distribution of relative abundances of the species according to the type of species (annual or perennial): a) semicovered fallow (Plot 1); b) weedy (Plot 2); c) intensive horticulture (Plot 3). 
Diversity refers to the variety of species that can be found in a community (Figures $4 \& 5$ ). The concept of diversity, in its simplest form, depends directly on the total number of species in the community (or floristic richness). However, it has been considered that it should also include the way in which abundance is distributed among the different species. This concept is called equitability, and the opposite concept is designated as dominance. A community with high dominance (or low equitability) is one in which a large proportion of the biomass is concentrated in a few species $[5,14,15]$. In this last community, the probability of detecting many of the species that constitute it is very low, therefore the diversity observed is also low. The species Lolium multiflorum and Trifolium Repens, showed a great dominance in all the managements, demonstrating a low equitability and a high dominance in the community in general. In horticultural use and weedy, one of the dominant species was also Oxalis latifolia [2,5]. Analyzing all the plots as a whole, it can be observed that they respond to the concepts of ecological succession raised by various authors in different ways and uses $[2,5,9]$. According to the bibliography, throughout the succession, that is, when the ecosystem tends to reach maturity, dominance in the community decreases and diversity increases, and in addition, there is a tendency to replace annual species with biannual or pluriannual (perennial), with a greater level of competition and survival in the absence of resources (K selection), as can be seen in (Figures $3 \& 5$ ) [5].

The coverage according to the linear intercept method was higher for the species Lolium multilflorurm, Trifolium repens and Lactuca virosa (Figure 6). In the rest of the horticultural production where an artificial forest (mount) predominated, the dominance of the Lolium multiflorum was total (100\%). The latter shows a great influence of the neighboring vegetation on the productive plots. In the surroundings of plot 2, the dominance of the species Lolium multiflorum was observed in two of the three repetitions of the frame method and in the linear intercept method, while in the remaining frame, a greater number of individuals of Trifolium Repens were recorded (Figure 6). The Lolium multiflorum species, which was observed to be dominant (in number of individuals) in almost all samples, is of the annual or biannual type, it means that its life cycle is relatively short, in comparison with the multiannual perennials $[4,16]$. On the other hand, although it was not the objective of this survey, when analyzing the height of the species, it should be noted that its size, on average, did not exceed 5 or $10 \mathrm{~cm}$. Both characteristics are typical of immature ecosystems, which is a state that systems reach when levels of disturbances are frequent or very intense $[2,3,18]$.
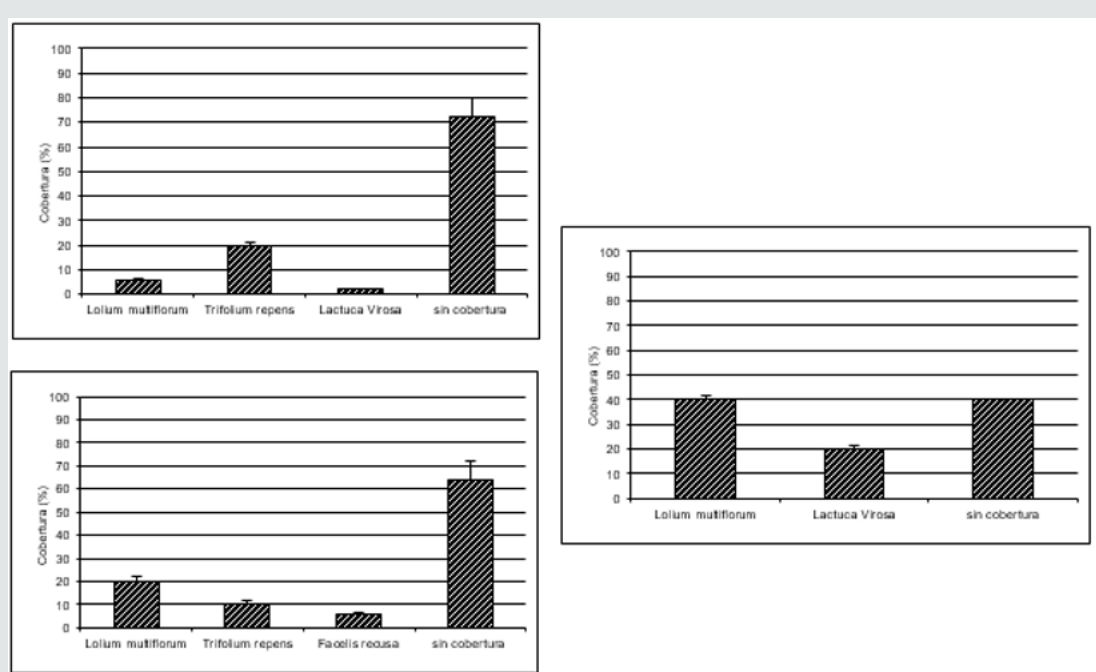

Figure 6: Coverage of the species according to the type of use: a) semi-covered fallow (Plot 1); b) weedy (Parcel 2); c) intensive horticulture (Plot 3).

The characteristics of the soil on which the horticultural production takes place and the addition of nutrients such as nitrogen (from the decomposition of vegetal remains, or compost), by the producers (huerteros), motivates the formation of a large source of resources $[7,8]$. As a result, species with $r$-type strategies were developed, with a high capacity for expansion and colonization, the latter may justify the presence of a large number of plants of the species Lolium multiflorum [11]. In addition, although the number of individuals per species was very high, the number of species per unit area was low: for example, the number of species surveyed in each repetition or frame. In contrast, the degree of dominance was high and was observed in those areas surrounding plots with moderate and intense degrees of disturbances $[2,4]$. In general, in the evaluated site, a great dominance of Lolium multiflorum was observed, because in this sector, and unlike the rest of the samplings, this species had a much higher height, which could be the result of its better development without disturbance some $[4,19]$. Its height, together with its higher density, determined new conditions for the future establishment of the "late" species in the succession. Moreover, this late species presents a better adaptation to shaded environments at ground level and with a better competition level for resources acquires. Due to this, the late species have a greater tendency to develop the $\mathrm{K}$ strategy, with greater competitive capacity and therefore, with enough power to displace the pioneers, in this case, Lolium multiflorum. However, because no other species were observed at ground level, it can be deduced that late species have not yet been able to establish or migrate to this place due to their recent anthropogenic disturbance $[2,11]$ (Figure 7). 

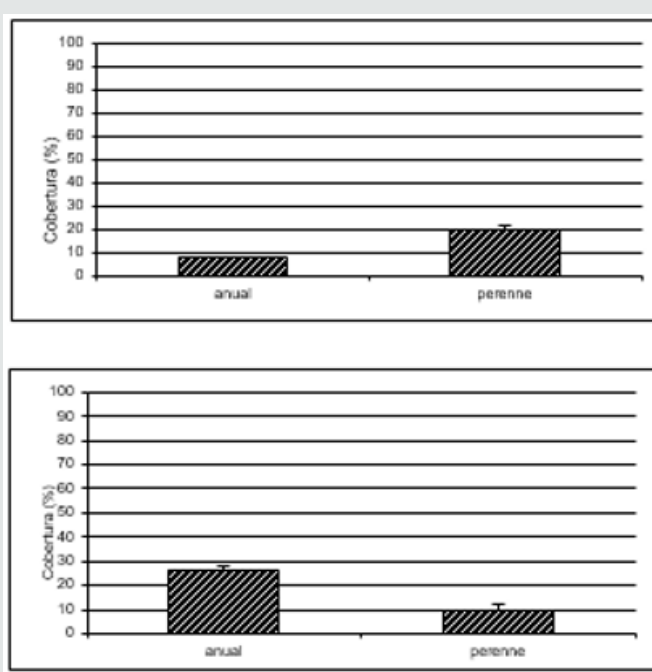

Figure 7: Coverage according to the type of annual or perennial species: a) semi-covered fallow (Plot 1); b) weedy (Parcel 2); c) intensive horticulture (Plot 3).

Beyond the concept that diversity is the justified manifestation of the coexistence of different species in a site, its usefulness as a descriptor lies in the possibility of establishing preliminary hypotheses about the way in which resources are distributed among different species and how they use the habitat in a particular environment and thus reflect on the mechanisms and factors that would be influencing the type of community structure [11]. The characteristics of the populations and plant communities indicated previously, are not more than expressions of the ecosystem that configure physiognomies of its structure and results of its functioning. In areas where the level of disturbance was lower (for example the plot with a high percentage of weeds), or directly null, it can be thought that the composition of the weed community will be similar to that of a mature ecosystem $[11,19]$. For example, this could be similar to comparing the cultivated area with the areas located in the neighboring sites or under the fences, or for example in the horticultural plots and in the headwaters or internal roads of the evaluated horticultural production $[4,5,19]$. Consequently, when studying the plot with minimal or no management, stands of plants surveyed could be considered as control plots. In this sense, these plots would be a reference to determine how modified this environment is or what degree of impact the disturbances have had in these horticultural environments or other cultivated sites. The latter allows us to understand and analyze in greater detail in what degree of succession is this system analyzed in particular. $[2,3,18]$.

\section{Conclusion}

Although a relationship could be established between the disturbances that occur in the plots and how these affect the plant communities inside and on the adjacent surfaces, disturbances may exist that are different from those that occur in each plot (for example, greater trampling by the circulation of the horticultural producers), which also influenced the composition and final coverage of the weed species. In those sectors where the disturbances are reduced or are practically nil, the appearance of perennial species is observed, both biannual and multiannual, although some in greater quantity than others. It can be deduced then that these communities present a higher degree of maturity due to the lesser influence of the disturbances, which has allowed a greater advance of the process of succession. However, there are still indications of dominance in them, which would indicate that they are mostly immature ecosystems.

\section{References}

1. Malacalza L (2013) Ecología y Ambiente Segunda Edición impresa, revisada y ampliada. Publicación del Instituto de Ecología y Desarrollo Sustentable de la Universidad Nacional de Luján y de la Asociación Civil Instituto de Ecología de Luján, Luján, provincia de Buenos Aires. ISBN 978-987-29821-0-2.

2. Nichols V, N Verhulst, R Cox, B Govaerts (2015) Weed dynamics and conservation agriculture principles: a review. Field Crop Res 183: 56-68.

3. Rolhauser AG, S Cepeda, PH Maseda, JL Rotundo, AM Srur, et al. (2007) Efectos de la frecuencia de corte y la fertilización nitrogenada sobre la estructura de una población implantada de Festuca arundinacea Schreb. Ecología austral 17(1): 89-98.

4. De la Fuente, EB Perelman S, CM Ghersa (2010) Weed and arthropod communities in soyabean as related to crop productivity and land use in the Rolling Pampa, Argentina. Weed Research 50(6): 561-571.

5. Ziska H, Dukes JS (2011) Weed Biology and Climate Change. Ames, IA: Blackwell Publishing Ltd, 68-205.

6. Mateucci, SD y A Colma (1982) Metodología para el estudio de la vegetación. Monografías O EA, Washington DC, USA, 22.

7. Coscarello EN, C Larregain, E Merluzzi, E Capasso, F Fernández, et al. (2013) Diagnóstico y propuesta de mejoras en la calidad higiénicosanitaria de hortalizas crudas en huerta orgánica periurbana Revista de la Facultad de Agronomía y Ciencias Agroalimentarias, Universidad de Morón 8 (4): 25-32.

8. Gliessman SR y P Tittonell (2015) Agroecology for Food Security and Nutrition. Agroecology and Sustainable Food Systems. Farming Systems Ecologist 39 (2): 131-133.

9. Odum HT, RC Pinkerton (1955) Time's speed regulator, the optimum efficiency for maximum output in physical and biological systems. American Scientist 43(2): 331-343.

10. Moreno Carrillo, Miguel A, Hernández-Garay, Alfonso, Vaquera-Huerta, et al. (2015) Productividad de siete asociaciones y dos praderas puras de gramíneas y leguminosas en condiciones de pastoreo. Revista fitotecnia mexicana 38(1): 101-108. 
11. Odum EP, GW Warret (2006) Fundamentos de ecología: Odum, Eugene P ( $5^{\text {th }}$ edn). México DF: International Thomson Editores.

12. Soriano A (1991) Río de la Plata Grasslands. In: R.T. Coupland (Ed) Natural Grasslands. Introduction and Western Hemisphere. Elsevier Cap 19: $367-407$

13. (2011) Instituto Nacional de Tecnología Agropecuaria (INTA).

14. Begon M, Harper JL, CR Townsend (1987) Ecología: Individuos, poblaciones y comunidades. edn. Omega, Barcelona, Spain.

15. Tilman D (1982) Resource competition and community structure. Princeton University Press, Princeton 17: 296
16. Aizpuru L Aseginolaza, PM Uribe-Echeberria, P Urrutia, I, Zorrakin E (1999) Claves ilustradas de la Flora del País Vasco y Territorios Limítrofes. Servicio Central de Publicaciones del Gobierno Vasco. Vitoria-Gasteiz, pp. 831.

17. Civeira G (2016) Potential changes in net primary productivity and carbon inputs in periurban agroecosystems treated with biosolids in Buenos Aires, Argentina. Pedosphere 26(1): 98-107.

18. McNaughton, SJ (1979) Grassland-herbivore dynamics. in: ARE Sinclair y M Norton-Griffiths (edns.) Serengeti: Dynamics of an Ecosystem. University of Chicago Press, p. 46-81.

19. Mc Naughton, SyL Wolf (1984) Ecología general. (1 $1^{\text {st }}$ edn) Ediciones Omega SA, Barcelona, Spain, pp. 724.

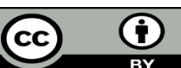

This work is licensed under Creative Commons Attribution 4.0 License

To Submit Your Article Click Here:

Submit Article

DOI: $10.32474 /$ OAJESS.2019.02.000137

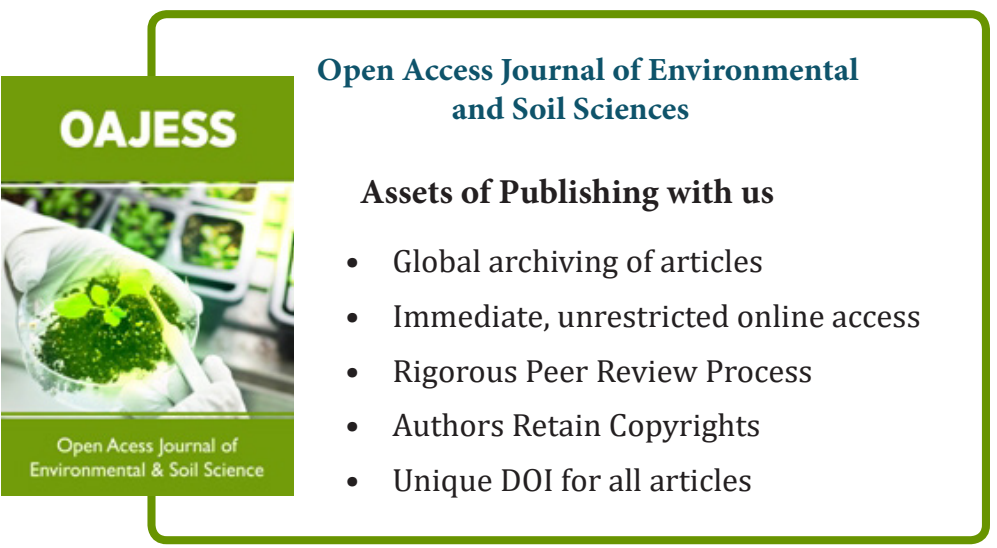

